\title{
Awakening Movement Consciousness in the Physical Landscapes of Literacy: Leaving, Reading and Being Moved by One's Trace
}

Rebecca J. Lloyd, PhD, Faculty of Education, University of Ottawa

Email: rlloyd@uottawa.ca

\begin{abstract}
Physical literacy, a concept introduced by Britain's physical education and phenomenological scholar, Margaret Whitehead, who aligned the term with her monist view of the human condition and emphasis that we are essentially embodied beings inthe-world, is a foundational hub of recent physical education curricular revision. The adoption of the term serves a political purpose as it helps stakeholders advocate for the educational, specifically literacy, rights of the whole child. Yet, one might wonder what impact conceptual shifts of becoming "physically literate" in lieu of becoming "physically educated" have on physical education research and practice. Terms such as "reading" the game and metaphors that describe the body as an "instrument of expression" are entering the lexicon of physical education but from a seemingly cognitive frame of reference. Arguably, the extent to which the adoption of physical literacy has on dissolving Cartesian views of the body and the mechanization of movement it performs has yet to be questioned. This article thus acts as an invitation to explore physical literacy in a Merleau-Pontian inspired act of inscribing the world through movement and how a reading of a reversible imprint might awaken a more fluent sense of what it means to become physically literate as new curricular pathways in the field of physical education emerge.
\end{abstract}

\section{Awakening Movement Consciousness in the Physical Landscapes of Literacy: Leaving, Reading and Being Moved by One's Trace}

Looking very broadly it could be suggested that the overarching characteristics of a physically literate individual are that the person moves with poise, economy and 


\section{Lloyd}

confidence in a wide variety of physically challenging situations. Furthermore the individual is perceptive in "reading" all aspects of the physical environment, anticipating movement needs or possibilities and responding appropriately to these, with intelligence and imagination (Whitehead, 2001, p. 3).

With a desire to awaken such "intelligence and imagination" as I orient myself toward Whitehead's definition of physical literacy, a concept that has influenced the curriculum of physical education worldwide (Whitehead, 2010), I begin with a brief reading of my environment in which much of my purposeful motility is situated. In so doing, a phenomenological turn to the thing itself, the world as it is experienced, will frame what Brown and Toadvine (2003) refer to as the "starting point" from which all philosophical evidence will arise.

Walking in the woods near my house always enlivens me, leaves an impression and invites me to press in as we experience a reciprocal embrace. Cherished childhood memories of spending hour-upon-hour soaking in the sounds of rustling leaves, trapeze-like tricks of scurrying squirrels and the magical quality of dewy patches of flora and fauna enter my present-day stride. Today, the freshness of the wind lifts my hair in a playful swirl as it caresses my cheek. My heart beats a little louder as I feel supported by the land always ready to bear the weight of my feet. Whatever the climate of my full yet stretched life, the earth, grass, mud, ice or snowcovered terrain is not only ready to receive me, it also playfully presses back. It perturbates or gently nudges my sole/soul out of an automaton-like existence, keeps me on my toes so to speak, and on occasion wakes me from moments lost in thought, as the rocks, roots and undulating hills react and rebound in the grounding consciousness of each stride. I am thus "drawn" into a synaesthetic soaking of sounds, sights and sensations living within the folds of the present moment.

Such a walk invites a questioning step into the present-day terrain of physical literacy (Whitehead, 2005; Ministry of Education, 2010; PHE Canada, 2010) with synaesthetic sensitivity, an attunement to the physical roots of literacy (Abram, 2010; Abram, 1996) and the possibility of recalling an animate connection with the world. Awakening movement consciousness in one's stride, as described in a walk in the woods, thus affords an opportunity to sense moments of enlivening that carry and flesh out the chiasm introduced by Merleau-Ponty's (1968) thesis of perceptual reciprocity through sensory intertwining. Such an orientation is timely as Ingold (2004) argues that the reversible sensation possible in the act of leaving a trace rarely enters a modern day consciousness. He attributes the loss of motile sensation to the hardened surfaces our feet now traverse, from paved sidewalks, streets and in the case of the physical education context, gymnasium floors and cement playgrounds. For the more impervious mother earth becomes to our motile acts, the degree to which one animate body may fold into, engulf 
and press out into the other, lessens.

\section{The Cartesian Tread}

Ingold (2004) theorizes, "People as they walk the streets, leave no trace of their movements, no record of their having passed by. It is as if they had never been” (p. 329). More than an absence of soft earth or snow in which one might press into, he continues to explain the presence of this perceptual "detachment, of persons from the ground, that runs as I have shown like a leitmotif through the recent history of western societies" (Ingold, p. 329). Such a detachment is significantly apparent in the ultimate mechanized pathway that supports the process of becoming more physically active within and beyond the physical education context - the treadmill. Farthest from its misleading etymology, the treadmill does not in the slightest provide a medium for imprinting one's tread. Rather, this surface promotes a Cartesian, mind from body disconnect as a walk or a run is perceptually shaped by luminescent screens that either quantify calories, distance, speed and time, or transmit television, a type of vision that veers one from the sensing body. Note that "tele" means "far off, afar, at or to a distance" (online etymology dictionary, 2011) and by watching television while walking, the direction of one's gaze does just that, creates a distance between what one is seeing from what one is physically doing. Such dissociation numbs what might be awakened if we were to experience the fullness of a tread in the chiasm of our breathing bodies (Gintis, 2007) and breathing world (Abram, 2010), a technological numbness that Ihde (2002) alludes to as a “thinning” within a possible “thickness” of Merleau-Ponty’s elemental flesh.

Technological inventions such as the treadmill are not the root cause for the mechanization of movement and the numbness present within and beyond gym walls. Cartesian dualism, a way of perceiving the mind as separate from a sensing body, most notably associated with Descartes' assertion that we think our way into existence, dates back to Plato and other ancient Greek philosophers. Although one might assume physical education to be a subject where students may be encouraged to use their sixth kinaesthetic sense and proprioceptively delve inside and dissolve body-as-object references, a "kinesthetic dystonia" resides where "for the majority of students training in movement, in the intricacies of the felt sense of the body, or even the ability to touch sensitively is near nil” (Myers, 1998, p. 103).

Embodied ways of knowing and being, therefore, stand in stark contrast to the dominant approaches to physical education pedagogy and program development that for the most part are influenced by the scientization of movement (Corbin \& McKenzie, 2008). Movement, within the "discipline” of physical education, as David Kirk (2010) explains, is taught in ways that are abstracted from their natural contexts through an "authoritarian pedagogy of command-response" (p.95). Opportunities for thinking in and through movement as articulated by Sheets-Johnstone (1999) are thus diminished as 
decontextualized, repetitive drills aimed at maturing movement have created a pedagogical paradigm of “physical education-as-sport-techniques” (Kirk, 2010, p. 42). Within this paradigm, movement of the body has lost its foundational connection to the vital breath as well as the animate world (Lloyd, accepted; Lloyd, in press a; Lloyd \& Smith, 2009; Conrad, 2007). Rather, attention is directed to the mechanistic break down of movement the Cartesian body performs where learning is narrowed to the process of acquiring sport-specific techniques, that if perfected, may be applied to a game (Rink, 2006).

\section{Moving Toward a Literacy of the Embodied Dimension}

Whitehead's intention for introducing the concept of physical literacy was to change educationalists' views on the priority of physical education that are for the most part influenced by "a Cartesian, dualist view of being, which casts the body as a mere mechanism” (Whitehead, 2005, p. 2). Informed by her doctoral readings of MerleauPonty and Sartre, Whitehead (2007; 2005; 2001) defined the concept of physical literacy through a "monist view of the human condition," the "centrality of our embodiment in existence,” and "our nature as essentially beings-in-the-world” (Whitehead, 2005, pp. 37). By introducing the concept of physical literacy, she intended that students acquire a "literacy of the motile aspects of the human embodied dimension" (2004, p. 4).

Upon further examination, however, one might question the extent to which a curricular shift toward physical literacy might change physical education praxis. Terms such as "reading the game" and metaphors that describe the body as an "instrument of expression" are entering the lexicon of physical education but from a seemingly cognitive or body-as-object frame of reference (Mandigo \& Holt, 2004; Killingbeck, Bowler, Golding \& Gammon, 2007). Attention in the act of “reading a game," for example, is thus directed to the process of tactical decision-making and formulation of appropriate responses. Similarly, the referral to the body as an "instrument of expression," as Whitehead (2010) acknowledges, perpetuates the Cartesian divide in such dualistic language. Metaphors are therefore useful for discerning meaning, not only "in language but in thought and action” (Lakoff \& Johnson, 2003, p.3). Hence, metaphors of reading and writing used to describe the process of becoming physically literate reveal interpretations and meanings associated with the adoption of this new curricular term, particularly with regard to its phenomenological roots.

The "building block" metaphor, common within the Canadian school and sport curricular uptake of physical literacy, (e.g., Ministry of Education, 2010; PHE Canada, 2010, 2008; Higgs, 2010) is another such metaphor that reveals how physical literacy is perceived. With a goal to move from fundamental movement skills to complex game play, the process of becoming physically literate has been described as the acquisition of foundational skills such as “walking, running, jumping, climbing, skipping, catching and 
throwing ...[which] provide a sound basis upon which all refined sport skills are based" (Francis, Johnson, Robinson \& Sheehan, 2011, p.14). For example, the premise put forward is that if you can run you will have the building block required to take part in games that are based on running such as soccer, baseball, volleyball, track and field, squash, badminton, rugby and tennis. If you can throw you will have the foundational skill to take part in activities that involve throwing such as baseball, softball, bowling and so on.

Whitehead (2010) reframes the building block, fundamental movement skill metaphor as a "bank of movement competences" (p. 53). Accordingly, the more one has in the bank, the more one will respond to a wide variety of situations in a way that is automatic to the individual. A physically literate individual who throws a ball within a game, for example, no longer has to stop and think to perform the movement, rather the motile act of "throwing" exists within a repertoire of movement possibilities. Whitehead (2010) refers to such movement patterns as one's vocabulary and relates the process of becoming fluent in such action to the Piagetian notion of assimilation and accommodation.

Just as Piaget, however, moves away from the sensing body in the prioritization of abstract thought in his formal operations stage, we too might pay caution to the inferred directionality within the building block (e.g., stacking) and banking (e.g., filling) metaphors. For as the focus moves toward progressive complexity, there is an inferred departure from what Sheets-Johnstone describes as "the realm of sheer kinetic 'I cans': I can stretch, I can twist, I can reach” (Sheets-Johnstone, 1999, p.136) within the primacy of movement. The focus thus shifts to the skills and techniques the objective body performs.

Evidenced within curricular supporting technologies such as Dartfish (2011), a software program that illustrates mechanistic breakdowns of fundamental movements and skills in various phases and sport contexts through visual representation of movement, an emphasis on the external body resides, an emphasis also apparent in the curriculum itself (Ministry of Education, 2010, p. 24). What appears to be missing within the praxis of physical education, one that has the potential to be transformed by the concept of physical literacy, is a poetic sense of movement, what Idhe (2010) describes as poesis within the Heideggerian notion of acquiring technique or "techné." If we are to transform the Cartesian ways of thinking about movement and the body as Whitehead desires, an invitation to experience the inner aesthetics, as in the kinaesthetics of movement is warranted. In sum, what has yet to be suggested within physical literacy curricular supporting documents (e.g., Francis et al., 2011) are ways in which a child may become more in touch with the natural world through the appropriation of a phenomenological and poetizing attitude. 


\section{Motion-Sensitive Phenomenology}

Rather than follow the trend of conceptualizing physical-literacy-as-fundamentalmovements-skills, i.e., conceptualizing walking and running as foundational building blocks for participating in more complex activities such as games and sports (Francis et al., 2011; Higgs, 2010), the intention of this phenomenological inquiry is to thus turn attention towards the grace and poetizing motility within the embodied dimension of motility, the "thing itself." Additionally, attention will be drawn to the degree to which motility is perceived and formed through a Merleau-Pontian chiasmic intertwining with the world. Such an inquiry will thus align with Whitehead's (2004) intention that the process of becoming physically literate cultivates a sense of being-in-the-world, a sense that "the environment is not an 'other' to us" (2004, p. 7) and that our movements are not necessarily informed from conscious decision, e.g., that at times, "the world itself can initiate action” (2004, pp. 7-8).

Inspired by Levin's phenomenology of movement maturation (1985), MerleauPonty's (1962; 1968) notion of reversibility, Sartre's (1956) sensualization of motile acts, Ingold's Merleau-Pontian informed perception of the environment, prior explorations into embodied experiences of flow (Lloyd \& Smith, 2006; Lloyd \& Smith, 2009; Lloyd, 2011; Lloyd, in press b), as well as David Abram's (1996; 2010) first person Merleau-Pontian inspired phenomenological description of moving in and being moved by the world, this inquiry delves into the possibilities of awakening a phenomenological movement consciousness, a "re-achieving [of] a direct and primitive contact with the world" (Merleau-Ponty, 1962, p. vii). With the intention of furthering curricular conceptions of physical literacy, therefore, this inquiry explores the phenomenon of leaving, reading and being moved by one's trace and thus serves to explore chiasmic perception within the landscape of an animate literacy.

A motion-sensitive (Lloyd \& Smith, 2006) approach to phenomenological inquiry (van Manen, 1997) is purposefully adopted as it invites first person, kinaesthetic accounts of moving and being moved by the natural world. What is unique to the motion-sensitive approach of phenomenology is that it emphasizes a shift from researching "lived experience" to the present moment dynamic nature of researching "living" and "still-tobe-lived" experiences with the purpose of inviting the reader into the pulse of the motile moment. The following passage from a chapter that details the motion-sensitive phenomenological approach (Lloyd \& Smith, 2006), informed heavily from the phenomenology of van Manen (1997; 2002), provides further context:

Motion-sensitive phenomenology emphasizes the transposition of the actions of living into the activity of writing and the latter's capacity to not simply re-enact or represent times and events past but to rejuvenate the ongoing practice of living well. Phenomenology, as the study of lived experience, recalls the details of life; but, as the study of living 
and still-to-be-lived experience, it inspires and invigorates us in the lives we lead. It is not "passive" in the sense of simply being inactive; on the contrary, there is a "receptive passivity," a "pathic" register of activity, a dispositional attunement, in other words, a motion sensitivity, that phenomenology cultivates. (Lloyd \& Smith, p. 293)

Through articulating a motion-sensitive phenomenological account of leaving, reading and being moved by one's trace, it is hoped that such a text may cultivate a sensitization to the magic of motility, not only within complex, euphoric moments of gliding but also within the simplest of acts such as walking, an otherwise mundane motion that has the potential to be so much more than a building block.

\section{A Phenomenology of Leaving and Reading One's Trace}

Sinking one's feet into the snow is a seductive act, an embrace of the environment, providing one doesn't stand motionless for any length of time. Bodily warmth and pleasure lives in the action of lifting of one's foot and propelling oneself forward while transforming and being transformed by the blanket of white that awaits.

I have over the course of the winter months, trekked out our own trail that connects our yard to the field behind our house; a trail my dog and I religiously follow until we eventually reach the margin of the woods where the hills and areas of fresh fallen snow beckon and call me into the reversible sentient folds of an elemental embrace. The landscape thus departs from a Western conception of "land," "nature" and "space," "a reject[ion of] the division between inner and outer worlds - respectively mind and matter, meaning and substance"(Ingold, 2000, p. 191). Rather, the horizon of fresh fallen snow which my dog and I approach "is within us [... it] becomes a part of us just as we are a part of it" (Ingold, p. 191), a phenomenon clarified by what Ingold describes as the difference between "nature" and "landscape" where the former is "explicate" while the latter is "implicate" (p. 191).

To be honest, I am not always fully immersed in the perceptual possibilities of such moments within the motility of each stride. My mind is usually sorting out events and stresses in my life as I begin our journey across the field. Perhaps the open, flat nature of the terrain invites my thoughts to swirl with the breeze. The intake of fresh air invigorates and inspires me and I embrace an indigenous link between thought and the wind (Cajete, 1994) and an etymological connection to the root of "inspiration" beyond the physical motion of detached respiration (Etymology Online, 2010). My consciousness thus vacillates between moments of crisp awakening as I 
enter the sound of my stride and experience "the [m]ind as wind, this whoosing force, the medium that moves between and binds all earthly beings" (Abram, 2010, p. 129) and vacated departure as my thoughts drift in suspended remembrance to moments that I cyclically relive or imaginatively refigure. I do not force myself into a present-moment awareness as the rhythmical nature of walking in the snow warms me, embraces me and provides me with an opportunity to enter what Claxton (1997) describes as a tortoise state of mind, a mental register that is "less purposeful and clear-cut, more playful, leisurely or dreamy, [a state that could be considered] a luxury [...] as life or work gets more demanding" (p. 2). My gaze is soft as I place trust in the path ahead. My feet lead me in what might be considered to be a warm-up, a low skilled, repetitive activity on relatively flat terrain. I do not need to look back and landmark where I have been for if I pause too long to reflect, a cool frigidity takes hold. Similarly, I do not need to look too far ahead as the well travelled path leads me to be exactly where I need to be, an eventual mind-body-world merge where the magic of motility emerges.

Such magic is experienced when there is a shift from reflectively remembering and recalling prior lived experience to awakening a pre-reflective consciousness that Merleau-Ponty (1962) attaches to a direct, spontaneous existence in and with the world, a relational existence that also approaches what Husserl describes as seeing the world with fresh un-jaded eyes (Silverman, 1980).

\section{Desiring a Trace}

What I see is the ending of my trekked out trail and the beginnings of a relational existence with unmarked snow, a canvas of sorts waiting to be transformed and in the same moment, transform me.

The blanket of white, the untouched terrain, as any avid snowshoer, skier or snowboarder may confirm, elicits a desire to traverse and merge with a sort of heaven on earth. Sartre (1956) relates such desire to the "digested indigestible" in that once one leaves tracks, the constitution of the snow will be forever changed. One might dream, like Sartre, of a "non-destructive assimilation [...one that contrasts the] unhappy fact - as Hegel noted that desire destroys its object” (p. 579). As the act of making fresh tracks traces one's pathway of desire yet, in the very act of expression, disrupts the blanket of whiteness, that which was once desired, and transforms its relational existence from that point forth. Perhaps it is the ideal of a virginal copulation, a desire of wanting to be the only one who presses into the animate other. If the snow were more like water as Sartre alludes, the trace or figurative inscription of a human-world embrace would soon disappear, recover and restore itself like the folding over of the wake left by a water-skier. For once when 
one leaves a trace in the snow it remains, vulnerable, until the heavens open once more. Sartre theorizes about such human-earth intertwining and delves into the realms of destruction and desire.

The idea of "carnal possession” offers us the irritating but seductive figure of a body perpetually possessed and perpetually new, on which possession leaves no trace. This is deeply symbolized in the quality of "smooth" or "polished." What is smooth can be taken and felt but remains no less impenetrable, does not give way in the least beneath the appropriate caress - it is like water. This is why erotic descriptions insist on the smooth whiteness of a woman's body. Smooth - it is what re-forms itself under the caress, as water re-forms itself in its passage over the stone which has pierced it. (Sartre, 1956, p. 579)

Perhaps a certain amount of selfishness takes hold in wanting to be the one to possess, in the carnal sense, and make one's mark. An avid snowboarder knows such desire as "fresh tracks” are motivation enough to wake up at the crack of dawn or to pay extraordinary amounts of money for a helicopter ride to a destination of powdery peaks....

I drift to memories of living in British Columbia and surfing down kneedeep powder with no need to excessively grip the terrain or add excessive torque to my turns. The subtlest of movements have a noticeably profound influence and I free myself to fall into the nuanced directions my head and shoulders lean, in some cases a full-on vertical drop. The euphoric rush of the moment washes over and flows within me and I glide toward multiple moments of motile ecstasy. Falling, as I fall in love with untouched terrain, is not a fear but part of a larger movement as I roll, rebound and leap with a gravity that holds me in a suspended embrace. For gravity, "once known as Eros - as Desire - the lovelorn yearning of our body for the larger Body of Earth, and of the earth for us" (Abram, 2010, p. 27) rises up into me as I become vulnerable to falling into a state of "off-balance" and I "tumbl[e] through the air..[...] the deep source of that conscious delirium that draws us toward the presence of another" (Abram, p. 27).

While its ancient Greek meaning indicates that "ecstasy" refers to a sensation of standing outside of oneself (Ackerman, 1999), I very much sense the inter-exteriority in the undulating sway of my stance. I am not rising out of my body but breathing into the grounding nature of my S-like trace that leaves behind an impression, a present moment phenomenon that will carry a remembrance of what lived in the fullness of smooth, rhythmical turns.

Similar to surfing on water, snowboarding has the possibility to educe an "ecstatic union 


\section{Lloyd}

with nature [as one experiences the sense of a] power that's greater than you" (Stranger, 1999, p. 270), one that must be respected as "the greatest power is closest to the curl [a place where] [a]potheosis and annihilation are separated by the narrowest of margins" (p. 271). For such reasons, one tends to relish one's earthly presence if one approaches an alluring yet terrifying crevasse of desire...

Perched beneath a mountainous lip of slippery ice, a rock smaller than my clenched fist stops my snowboard from gliding into a crevasse-like chute of jagged terrain. A dawning reality of my powder-chasing adventure registers. Fear creeps into my legs, stomach and into my chest as I see the sun glimmer off the rocks below. The coldness of the ice's surface presses into my buttocks as my cheeks leave a potential final impression. A pervasive shake seeps into my bones. Time passes. The sun once yellow begins to take on a shade of reddish pink. I soften my gaze and let his glow soak into me. His warmth pushes the rising fear back down to my feet and into the rock beneath my board. The trembles dissipate as I fully take in the horizon, wondering if today will be my last. I begin to "feel privileged to be intermingled and intermingling with this beautiful flesh - this flesh of the world that has folded over and touched me, here, into feeling, not only awed 'in response' to it, but also so beautifully enlivened" (Cataldi, 1993, p. 120). My heart now pulsates in unison with a sky that no longer haunts but envelopes and radiates. Not detached, I sense what Vincent van Gogh made visible, "a plenum of light-filled sky that [has] its own temporal dynamism, its own rhythm, its pulse” (Abram, 2010, p. 50). I feel all that is present within "the vertical visible world [...] not made of a multitude of memories, images, judgments, [but..] one sole cluster as a spontaneous 'word' contains a whole becoming, as one sole grasp of the hand contains a whole chunk of space." (Merleau-Ponty, 1968, p. 236)

\section{Destructive Desire}

Living within the margins between life and death, the precarious moment where life is both suspended and dangled by mother nature's outstretched palm is not unique to a snowboarder on the hunt for heavenly "out-of-bounds" powdery terrain. Any athlete attracted to high-risk sport has the potential to experience the double-edge mobility/morbidity sword of progressive speed, pitch and/or torque. Joe Simpson, a climber who has experienced both elation as well as impending doom, for example, describes a moment of living life by a thread:

At last we fell silent. A terrible fear and insecurity had overtaken our boisterous reaction to the unimaginable event. Shining torches below, we saw the remains of our two ropes, which had been hanging beneath 
the ledge. They were cut to pieces, shredded by the falling rock. Turning round to inspect the safety line, we were appalled to find that the old ring peg on which we hung was moving, and that the spike of rock had been badly damaged. It looked as if one of the two attachment points would give way at any moment. We knew that if just one anchor point failed we would be hurled into the void. [...] We hung on that fragile rope for twelve interminable hours. Eventually our shouts were heard and a rescue helicopter succeeded in plucking us from the wall. The experience of that long, long night, expecting to fall at any time, one minute laughing hysterically, then silence, always with stomachs clenched, petrified, waiting for something we did not wish to think about, will never be forgotten. (Simpson, 1997, pp. 38-39)

While such moments magnify the most primal sensations of being alive, from the thumping sound of one's heart beat to perceptions of a typically hidden visceral motility, one might question the desire that draws one into such a state of existence. Csikszentmihalyi, a motivational psychologist, posits such an experience within his theory of "flow," a highly engaging, all-consuming experience where existentials such as lived time and body are altered due to an engagement in a progressively complex activity where the skill required to sustain it is precariously balanced with a corresponding level of perceived challenge (Csikszentmihalyi, 2000, 1997, 1996). Such a skill-challenge relationship, a progressive directionality that aligns with the upward push toward complexity within the fundamental movement skill conception of physical literacy (e.g., Higgs, 2010) might be challenged, as in redirected, as we consider alternatives to the upward climb. Stephen Smith (2006), for example, offers an alternative, more provocative postulation. He speaks of the kinetic desire to reach out to the world around us and feel a:

compelling sense of connection, [in...] being embraced by the world, sensuously, erotically, corporeally [..by... the carnal moment, vulnerable in another's arms, caressed and soothed in a capacious intimacy. It is "the instant" that "contains the moment as a tear contains the ocean" (David, 1996, p. 58). It is an embrace that contains the world, if but for a moment. (Smith, 2006, p. 3)

Perhaps for this reason, athletes are moved to desire a sense of heaven on earth, a sensation that extends the perceptive flesh of the body to sensuously include an elemental embrace, a merge with an animate earth that has the potential to elicit a fathomless sense of both terror and beauty. Rilke's first elegy, speaks to such moments of elemental desire, a "terror we can hardly bear, and we adore it because of the serene scorn it could kill us with. Every angel's terrifying...” (Rilke, as translated by Poulin, 1977, p. 5) as the alluring yet potentially fatal draw of a virginal crevasse-like copulation opens itself up in the possibilities of a human-world merge. 


\section{Lloyd}

I am awakened from my blissful blur of sensing the chiasmic touching touch of the setting sun. Five men arrive out of the blue on a joyous out-ofbounds adventure of their own. They assess my situation and within minutes form a human chain. I look up into the eyes of a stranger whose hand now touches mine. He instructs me to turn inward to face the mountain. My life dangles in his outstretched arm. With his assistance, I hop the inside edge of my snowboard toward the top. I look up to catch my bearings and begin to thank the...I rub my eyes and see the outer form of my rescuers slip off into the horizon. Their angelic presence fades just as quickly as they arrived.

More than a thrill to progress skill to a complex level, Rilke's poetry inspires one to consider the primal need to fill the loneliness of an empty embrace and jump into the arms of a lover be it snow, rock or human flesh, a kinetic act that has the potential to free “our ancient suffering” (Rilke as translated by Poulin, 1977, p. 7). Yet in so doing, letting oneself fully fall into the chute of jagged terrain and embrace Rilke's angel presents the possibility of an almost certain end to lived human existence. To step into the possibility of moving beyond an existence where life hangs in the "state of the soul, in which all its motions are suspended, with some degree of horror" (Burke, 1958, p. 57 as cited in Stranger, 1999, p. 270) or wonder, the emotion Sue Cataldi (1993) associates with "a mesmerizing sort of depth on the surface of a fascinating spectacle - a depth which I am so to speak inscribed... one which I am (involuntarily) 'fastened' or 'glued'” (Cataldi, 1993, p, 11) requires that one search for a more tenable terrain.

\section{Maturing a Trace}

The depth of the snow in which my snowshoe now sinks draws me back into the present moment. No longer in the backcountry of Blackcomb mountain sensing the euphoric glide of aliveness while riding the double-edge possibility of morbidity, my motile connection with nature takes a mature turn. The ebb and flow of delicate rolling hills, comparatively perceptually flat, unfold in a sensuous magic that I have come to savor.

Sartre (1956) suggests that in leaving such a trace,

by my very activity as a [snowshoer], I am changing the matter and meaning of the snow. From the fact that now in my course it appears to me as a slope to go down, it finds again a continuity and a unity which it had lost. It is at the moment connective tissue. It is included between two limiting terms; it unites the point of departure with the point of arrival. (p. 582) 
A reading of such a trek points to the obvious shift in the pathway of desire. No longer fixated "on a point to be reached beyond the position which I now occupy" (Sartre, p. 582) the details possible to sense at a slower, more grounded pace open up.

My trace in the snow tells a new story. No longer relying on lift ticket to lift me up to the mountainous peaks, to "the motility of an ego-logical agent [...I am now beginning to embrace] the poetizing motility of someone gracefully following [her] own path, and passing through the world in a way that somehow enriches all the beings of earthly dwelling" (Levin, 1985, p. 105-106). What I see, hear and feel is more than the singular direction of a snowballing rush. An attentive tracker of my new path would notice moments of depth in my reciprocal imprint, moments where I sink a little deeper to soak in the presence of the Other. Visible traces of deer, rabbits, and on some occasions, foxes and wolves broaden my peripheral consciousness, tracks that while certainly present, never entered the realm of the visible in my former euphoric ride. A natural curiosity and appreciation for an animate presence takes hold as I crouch to photograph clusters of animal prints.

\section{Reading a Trace}

The more I attend to the traces an animate other left behind, it becomes increasingly obvious that I am not fluent in distinguishing the track of one deer from another, the freshness of the trace or the details read by indigenous hunter and gathering cultures, for reasons of survival, where the "specifics of the natural world are named" (Brody, 2000, p. 12). The physicality of becoming literate in this sense has more to do with sensing details of a lived moment, it's earthly depth where "eyes converge upon a visible mark, or a series of marks, yet what they find there is a sequence not of images but of sounds, something heard [something felt, where...] a new linkage has been forged between seeing and hearing which ensures that a phenomenon apprehended by one sense is instantly transposed into the others" (Abram, 1996, p. 124). Thus a synaesthetic reading offers a tangible movement toward approaching the physicality of literacy, a way of seeing and reading a trace, such as the marks left by my snowshoes or my former S-like curves on an alpine slope, that may reveal the living details of what was experienced.

Compared to a reading of an elemental embrace within the powdery peaks and folds of desire, however, such a reading of my tracks showing pause to read animal tracks reveals an imprint that no longer desires a carnal merge. The elemental embrace thus shifts from 


\section{Lloyd}

the intertwining of lovers to mothers, siblings or the casual hug shared between good friends. Not to be downplayed, however, a fluency in reading the trace of mother, sister or friends of the earth also has the potential to awaken a chiasmic connection with the world. Take for example, what was revealed to Houle (2007) who experienced her "exercise" in the woods in the company of an animal tracker.

My good friend, Bruce is an animal tracker. [...] I went to visit him last winter [...] One of the first things we did was go for a run in the bush [...] While running Bruce was looking intently left and right, even overhead, and making the odd squawking sounds. I can't hear anything when I run except my laboured breathing, and I can’t see anything except the tops of my running shoes, and the path below them. When I run I am exercising. I asked him later what he was doing? "Checking in on folks," was his reply: 'folks' being the birds, coyotes, owls, deer; really anything within the moving circle of his perception and impact. When Bruce runs he is visiting. (p. 239)

Shifting perception from human-centric terms to "visiting," orients us to what it might be like to slow down and attend to the sensations and sentient beings living within our vibrant world. Houle describes what it is like to experience such a perceptual shift, from her focus of caloric expenditure and sounds of her laboured breath to what lies beyond the tip of her nose.

Spending time with a tracker is like going down the rabbit hole into the main ballroom of one's perception and finding a big party underway. The world we move around in is fully occupied, fully inscribed, at the same time and in the same places as we find ourselves, by our animal, feathered, vegetable and insect kin. [...] Usually we are too busy thinking about something else, or searching for something we think and hope will be there, or making noises thus not hearing them call the name they have for us, or sticking too closely to the path. Literally and metaphorically. But once we do notice, become aware, learn the rudiments of their signs, the questions which those encounters pose, are very good ones. They too, open unexpectedly onto other underground tunnels of further questions. Possible answers to those questions shake our sense of the world: a shaking orders of magnitude greater than one would think a little hunkering rabbit capable of. (2007, p. 245)

Just as a seasoned tracker may acquire a fluency and a sense of appreciation in reading the animal world, the possibility to develop a similar fluency in reading the tracks humans leave behind, such as the trace of a skate, snowboard or ski leaves in the snow becomes plausible. More than a uni-dimensional pathway of an imprint that maps how one traverses from point $\mathrm{A}$ to point $\mathrm{B}$, a possibility to sense and imagine the bodily 
alignment, rhythm, consistency, force and sense of bound or continuous flow required to make such an impression may emerge. While much of Laban's (1948) movement analysis has been directed to analyzing bodies in motion, we may thus apply his principles of effort to develop an embodied understanding of "physical literacy" through reading the trace one leaves behind.

\section{Moving within a Trace}

If one took a detailed look at the steps made within my snowshoeing path, for example, a slight supination would become visible, a physical reminder of my former life as a professionally trained ballerina, a time when weight directed to the outer edges of my feet maximized a turned-out stance. One would also note, however, that this weight-bearing pattern was not cause for waver as the consistent distance between strides, secure landings from jumps off jutting out rocks and treks made between tightly squeezed trees indicate a certain amount of lightness, grace, and agility was experienced. Hence, sensitizing the notion of "poise" articulated in the process of becoming physically literate by Whitehead (2001) is possible. As one continues to read the trace left behind, one might also discern a sense of developmental maturity, a concept within Levin's (1985) existential offering of the genesis and unfolding of motility. As one becomes ontologically ontic (aware, openness-for-Being), the characteristics of such motility may be described as being "grounded, poised, balanced, graceful, flowing, relaxed, open, dance-like, free, serene, agile, manifesting, equanimity, ready to let go, tender, gentle, caring, mindful, lively, firm, fitting” (Levin, 1985, p. 114). Imagine then how these characteristics could become embodied and left within the trace of one's stride. Could it be possible to discern such a presence in movement quality compared to that which is evident in "how most people today experience walking, and how the linear system of concrete sidewalks we build reflects our attitude and our experience" (Levin, p. 104)? While the focus of Francois Delsarte's work in the late 1800's was to detail such intricate physical manifestations of motile expression, the dispositions inherent within the nuances of bodily positions (an approach to analyzing movement that was a precursor to the notation put forward by Laban some years later), the ability to read such expression was coined a form of "literacy." As a modern dance educator who immersed himself in reviving the Delsarte approach to reading the details of expression, Ted Shawn concluded that such bodily attentiveness, what he coined "physical literacy" should be at the heart of physical education programs. He writes:

I hope the day comes when all children, from their first start in the primary grades, learn to use human movement as a language equally and along with their learning to communicate by speech and by writing. We would then have in a few generations a physically "literate" adult population; for today, in spite of "physical education" (which confines itself largely to teaching athletic sports) we have mostly physical 
illiteracy - only one in a million can communicate and read communications through gesture... (Shawn, 1965/1968, pp. 89, 90)

Combining such a reading of bodily gestures with a detailed reading of the traces one leaves behind has the potential to offer new meaning within our present day curricular terrain. Synaesthetically, as in amalgamating the visual, kinaesthetic, auditory, and olfactory senses, in reading the specific, meaningful details in the trace one leaves behind thus stands in contrast to the typical skill-building, exterior emphasis on movement taught within the physical education context. For example, while some might consider a walk to be a building block of sorts to bigger, more skillful actions, there is something quite profound in the lightness, agility and rhythmical nature that gives the optical illusion of a phrase-like glide evident in the way a professionally trained ballerina moves across a stage. The dancer walks with the intention of not leaving a trace in a magical moment of suspension. Much attention is thus cultivated in maturing a dancer's walk as the simplest of motions reveal so much, just as a single note played through a wind instrument may reveal the presence of a virtuoso (Ihde, 2010). Paint-dipped feet may provide a possibility for tracing a dancer's motion, however, the added texture would diminish its lightness and silence. Hence, the shortcoming of becoming overly reliant on physically reading a movement's trace as a mode of approaching physical literacy is that in some instances, nothing physical remains.

\section{Transcending a Trace}

But as I continue to walk in the snow and reciprocally sense what is also pressing into me, I also wonder to what extent a reading of my tracks will reveal the feeling of being embraced by the world present within my countless journeys, a sensation ingrained within my motile consciousness. Such a sensation also leaves no trace. I know that I have left my physical mark on the landscape as spring has turned into late summer and the trace of my trek remains. Considering that "paths and tracks "impose a habitual pattern on the movement of people [a]nd yet they also arise out of that movement” (Ingold, 2000, p. 204), to what extent will this reciprocal Merleau-Pontian chiasm of sensation be read and sensed by others who follow my path? No longer alone in my footsteps of awakening, I see on occasion others walking their dogs who traverse my tracks and wonder if they too sense "a feeling for the organism" (Kellor, 1983, p. 198), the sense of aliveness within the animate earth? More than likely, their eyes will not "see the myriad signs of life that a casual eye misses” (Kellor, p. 200) as my trekked out trail serves a practical purpose, a convenient shortcut that connects Old Chelsea Road to the open fields and margins of the nearby forest. I find comfort in knowing that while others who now press into what my feet lovingly inscribed might not read the nakedness of my emotive impressions, the ground remembers. Call me sentimental, but tears that seep in wanting to hold on to the untenable reality that my feet may be the only ones to press into and be held by this path release and comfort me. Do they not know that I have on occasion penetrated my earthly 
mother and found solace in stepping into the arms of an elemental lover, a delicate crevasse carved from my feet that support a physical activity with leman sensitivities? No matter. The pulse of such a world not only presses into me, it continues to shape a consciousness formed by the chiasmic nature of a self-world merge. My path continues to support and press into me, regardless of the utility it now serves, as I continue to transcend beyond the practical function of becoming physically active to walk my dog. A sense of the sacred remains...

\section{Conclusion}

As we step on the path of curriculum transformation, shaped by the existential and foundational concept of physical literacy, I wonder, what sensations might now become ingrained? In sharing such an intimate, phenomenological exploration of my traces in the snow, mud and grass that shape my countless motile journeys in the fields and forest behind my house, I wonder how this might contribute to a curricular understanding of physical literacy. Could students be encouraged to find special, even sacred spaces and places that could awaken them on their pathways to becoming more fit and physically active within and beyond the milieu of physical education? And what might be gained in asking them to keep reflective journals with prompts that encourages students to pay attention to the details of their movements, the imprints left by chiasmic impressions made by their feet and the story in tracing their chosen pathway that might emerge? Such an approach would add a qualitative dimension to recent quantitative approaches to assessing physical literacy with externally-based measures of performance (Tremblay \& Lloyd, 2010) that arguably perpetuate a Cartesian divide.

But, difficulties in delving past the flattened and hardened surfaces that support much of the physical activity experienced in the context of physical education remain. How can we as educators and researchers of physical literacy in urban environments encourage an existential intertwining in a developmental movement consciousness? Martusewicz (2005) describes some of the ways she helps school children reclaim a connection to the natural world by asking them to think of "the earth that exists under their sidewalks as living soil that feeds the mature trees helping to clean the air" (p. 344). More than an abstraction, if brought to a site of construction children might be reminded of the terrain that exists even through a tele sort of vision. Ideally though, fieldtrips, as in trips to actual mud or snow-laden fields, where children do more than imagine but physically press into the earth are worth taking. Once there, as in soles experiencing the reversible imprint of the earth, we might reacquaint ourselves with the perceptual possibilities of what lives within one's stride and in so doing deepen syn/kin-aesthetic understandings of what it might mean to become physically literate in an animate world, an understanding of literacy that might appeal to the field of literacy at large. David Abram (2010) reminds us that: 
Our commonplace practice of reading texts has its deepest ancestral source in the indigenous hunter's careful reading of animal tracks pressed into the surface of the earth. But the recent transformation of this ancient craft into a purely human reading of our own tracks, trailing off across the page or screen, has made possible a degree of human selfinvolvement entirely unknown to our oral ancestors. Today, printed words such as these you're reading circumscribe a symbolic space of communication that we carry solely among ourselves, a hyperreflective style of cognition far too abstract to register the incarnate intelligence of other animals (often so detached that it renders us, while we're reading, oddly impervious to the promptings of our own animal flesh). The powerful, self-enclosed spell of the written letters easily eclipses that subtler magic - the nuanced exchange between the human animal and the animate earth. (Abram, 2010, pp. 206-207)

Delving into "that subtler magic" Abram articulates by awakening movement consciousness in one's stride thus provides a possible pathway for inscribing curricular understandings of what it might mean to become physically literate within and beyond the physical education context. Perhaps then an ontological shift away from the Cartesian body and an embrace of Whitehead's desire to cultivate an embodied sense of being-inthe-world is possible. Cultivating a connection to the natural world thus has the potential to shape the quality of our lives in the simplest yet profound act of walking and the motile possibility of leaving, reading and being moved by one's trace. Hence, a chiasmic sensibility in experiencing a curriculum, shaped by the foundational concept of physical literacy, has the potential to be figuratively, fluidly, and fondly lived.

\section{References}

Abram, D. (1996). The spell of the sensuous. New York, NY: Vintage Books.

Abram, D. (2010). Becoming animal: An earthly cosmology. New York, NY: Pantheon Books.

Ackerman, D. (1999). Deep play. New York, NY: Vintage Books.

Brody, H. (2000). The other side of Eden (Ch. 4, Words). New York, NY: North Point Press.

Brown, C. S. \& Toadvine, T. (2003). Eco-Phenomenology. Albany N.Y.: State of New York Press. 
Cajete, G. (1994). Look to the mountain: An ecology of indigenous education. Durango, CO: Kivakí Press.

Cataldi, S. (1993). Emotion, depth, and flesh: A study of sensitive space: Reflections on Merleau-Ponty's philosophy of embodiment. Albany, N.Y.: State University of New York Press.

Claxton, G. (1997). Hare brain tortoise mind. Why intelligence increases when you think less. Great Britain: Fourth Estate Limited.

Conrad, E, (2007). Life on land: The story of continuum. Berkeley, CA: North Atlantic Books.

Corbin, C. B., \& McKenzie, T. L. (2008). Physical activity promotion: A responsibility for both K-12 physical education and kinesiology. Journal of Physical Education, Recreation \& Dance (JOPERD), 79(6), 47-56.

Csikszentmihalyi, M. (2000). Beyond boredom and anxiety: Experiencing flow in work and play. San Francisco, CA: Jossey-Bass Publishers.

Csikszentmihalyi, M. (1997). Finding flow: The psychology of engagement with everyday life. New York, NY: Basic Books.

Csikszentmihalyi, M. (1996). Creativity: Flow and the psychology of discovery and invention. New York, NY: Harper Collins.

Dartfish (2011). Education Software- Physical Education. Retrieved from http://www.dartfish.com/en/education_software/physical-education.htm

Etymology Online (2010). Inspiration. Retrieved from http://www.etymonline.com/index.php?search=inspiration\&searchmode=none

Francis, N., Sheehan, D., Robinson, D., \& Johnson, A. (2011). An educator's guide to teaching fundamental movement skills. Ottawa, ON: Physical and Health Education Canada.

Gintis, B. (2007). Engaging the movement of life: Exploring health and embodiment through osteopathy and continuum. Berkeley, CA: North Atlantic Books.

Higgs, C. (2010). Physical literacy - Two approaches, one concept. Physical \& Health Education Canada Journal, Spring, 6-7. 
Houle, K. (2007). (Making) animal tracks. PhaenEx: Journal of Existential and Phenomenological Theory and Culture, 2(2), 239-259.

Ihde, D. (2002). Bodies in technology. Minneapolis, MN: University of Minnesota Press.

Ihde, D, (2010). Heidegger's technologies: Postphenomenological perspectives. New York, NY: Fordham University Press.

Ingold, T. (2000). The perception of the environment: Essays in livelihood, dwelling and skill. New York: Routledge.

Ingold, T. (2004). Culture on the ground: The world perceived through the feet. Journal of Material Culture, 9, 315-340.

Kellor, E. F. (1983). A feeling for the organism: The life and work of Barbara McClintock. San Francisco, CA: W.H. Freeman.

Killingbeck, M., Bowler, B., Golding, D., \& Sammon, P. (2007). Physical education and physical literacy. Physical Education Matters. 2(2), 21-23.

Kirk, D. (2010). Physical education futures. New York, NY: Routledge.

Laban, R. (1948). Modern educational dance. London, U.K.: Macdonald and Evans.

Lakoff, G. \& Johnson, M. (2003). Metaphors we live by. Chicago, IL: The University of Chicago Press.

Levin, D.M. (1985). The body's recollection of being. London, U.K.,: Routledge.

Lloyd, R. J., \& Smith, S. J. (2006). Motion-sensitive phenomenology. In K. Tobin \& J. Kincheloe (Eds.), Doing educational research: A handbook (pp. 289-309). Boston, MA: Sense Publishers.

Lloyd, R.J. and Smith, S.J. (2009). Enlivening the curriculum of health-related fitness Educational Insights, 13(4). Available: http://www.ccfi.educ.ubc.ca/publication/insights/v13n04/articles/lloyd_smith/inde $\underline{\text { x.html }}$

Lloyd, R. J., \& Smith, S. J. (2010). Feeling "flow motion” in games and sports. In J. Butler \& L. Griffin (Eds.), Teaching games for understanding (pp.89-103). Champaign, IL: Human Kinetics. 
Lloyd, R. J. (2011). Teaching games with inner sense: Exploring movement consciousness in women's volleyball. PHEnex journal/revue phénEPS, 3(2), 1-17.

Lloyd, R. J. (accepted). Running with and like my dog: An animate curriculum for living life beyond the track. Journal of Curriculum Theorizing.

Lloyd, R. J. (in press a). Moving to learn and learning to move: A phenomenological exploration of children's climbing with an interdisciplinary movement consciousness. The Humanistic Psychologist.

Lloyd, R. J. (in press b). A continuum of fluid movement consciousness: Approaching interdisciplinarity in health-related fitness curriculum and pedagogy. uOttawa Education Review.

Mandigo, J. L., \& Holt, N. L. (2004). Reading the game: Introducing the notion of games literacy. Physical and Health Education Journal, 70(3), 4-10.

Martusewicz, R. (2005). Eros in the commons: Educating for eco-ethical consciousness in a poetics of place. Ethics, Place and Environment, 8(3), 331-348.

Merleau-Ponty, M. (1968). The visible and the invisible (Alphonso Lingis, Trans.). Evanston, IL: Northwestern University Press.

Merleau-Ponty, M. (1962) Phenomenology of perception (Colin Smith, Trans.). London, U.K.: Routledge \& Kegan Paul.

Ministry of Education (2010). The Ontario curriculum, Grades 1-8: Health and physical education, Interim Edition. Retrieved from www.edu.gov.on.ca/eng/curriculum/elementary/health.html

Myers, T. (1998) Kinesthetic dystonia: what bodywork can offer a new physical education. Journal of Bodywork and Movement Therapies, 2(2) 101-114.

Online etymology dictionary

http://www.etymonline.com/index.php?search=tele\&searchmode=none

PHE Canada (2008). FMS tools for schools. Retrieved from www.canadiansportforlife.ca/upload/.../FMS\%20Tools\%20for\%20Schools.pdf

PHE Canada (2010). Physical literacy in Canada. Retrieved from http://www.phecanada.ca/developingphysicalliteracy/e/ 
Rilke, Rainer Maria, (1977). Duino Elegies and the sonnets to Orpheus (A. Poulin, Jr., Trans.). Boston, IL: Houghton Mifflin Company

Rink, J.E. (2006). Teaching physical education for learning (5th ed.). Toronto, ON: McGraw-Hill.

Sartre, J. P. (1956). Being and nothingness: An essay on phenomenological ontology. New York, NY: Philosophical Library.

Shawn, T. (1965/1968) Every little movement: A book about François Delsarte: The man and his philosophy, his science and applied aesthetics, the application of this science to the art of the dance, the influence of Delsarte on American dance. Brooklyn, NY: Dance Horizons

Sheets-Johnstone, M. (1999). The primacy of movement. Philadelphia, PA: John Benjamins Publishing.

Silverman, H. J. (1980). Phenomenology. Social Research, 47(4), 705-720.

Simpson, J. (1997). Touching the void. London, U.K.: Vintage.

Smith, S.J. (2006). Gesture, landscape and embrace: A phenomenological analysis of elemental motions. Indo-Pacific Journal of Phenomenology, 6 (1), 1-10.

Stranger, M. (1999).The aesthetics of risk: A study of surfing. International Review for the Sociology of Sport, 3(34), 265-276.

Tremblay, M. \& Lloyd, M. (2010). Physical literacy measurement - The missing piece. Physical and Health Education Journal, 76(1), 26-30.

van Manen, M. (1997). Researching lived experience: Human science for an action sensitive pedagogy. London, ON: The Althouse Press.

van Manen, M. (2002). Writing in the dark: Phenomenological studies in interpretive inquiry. London, ON: The Althouse Press.

Whitehead, M. E. (2001). The concept of physical literacy. British Journal Teaching of Physical Education. Retrieved from http://www.physical-literacy.org.uk/concept-abstract.php

Whitehead, M.E. (2004) Physical literacy - A debate - Pre-Olympic Congress Thessaloniki. Retrieved from http://www.physical-literacy.org.uk/greece2004abstract.php 
Whitehead, M. E. (2005). Physical literacy- A developing concept. British Journal Teaching of Physical Education. Retrieved from http://www.physicalliteracy.org.uk/durham2005-abstract.php

Whitehead, M. E. (2007). Physical Literacy: Philosophical considerations in relation to the development of self, universality and propositional knowledge. Sport Ethics and Philosophy 1(3), 1-27. Retrieved from http://www.physicalliteracy.org.uk/sport-ethics-philosophy-2007-abstract.php

Whitehead, M. (2010). Physical literacy: Throughout the lifecourse. New York, NY: Routledge. 